University of Nebraska - Lincoln

DigitalCommons@University of Nebraska - Lincoln

USDA National Wildlife Research Center - Staff Publications
U.S. Department of Agriculture: Animal and Plant Health Inspection Service

2000

\title{
Evaluation of a Radar-Activated, Demand-Performance Bird Hazing System
}

\author{
Gwen R. Stevens \\ Department of Biology. Colorado State University, Fort Collins \\ Jamie Rogue \\ Colorado State University, Fort Collins, Deparrmenrof Fisheries and Wildlife \\ Richard Weber \\ Knight Piesold and Cornparry. Denver, CO \\ Larry Clark \\ USDA/APHIS/WS National Wildlife Research Center, larry.clark@aphis.usda.gov
}

Follow this and additional works at: https://digitalcommons.unl.edu/icwdm_usdanwrc

Part of the Environmental Sciences Commons

Stevens, Gwen R.; Rogue, Jamie; Weber, Richard; and Clark, Larry, "Evaluation of a Radar-Activated, Demand-Performance Bird Hazing System" (2000). USDA National Wildlife Research Center - Staff Publications. 835.

https://digitalcommons.unl.edu/icwdm_usdanwrc/835

This Article is brought to you for free and open access by the U.S. Department of Agriculture: Animal and Plant Health Inspection Service at DigitalCommons@University of Nebraska - Lincoln. It has been accepted for inclusion in USDA National Wildlife Research Center - Staff Publications by an authorized administrator of DigitalCommons@University of Nebraska - Lincoln. 


\title{
Evaluation of a radar-activated, demand-performance bird hazing system
}

\author{
Gwen R. Stevens ${ }^{a}$, Jamie Rogue ${ }^{b}$, Richard Weber ${ }^{c}$, Larry Clark ${ }^{d, *}$ \\ a Department of Biology, Colorado State University, Fort Collins, CO 80523, USA \\ ${ }^{b}$ Department of Fisheries and Wildlife, Colorado State University, Fort Collins, CO 80523, USA \\ ${ }^{'}$ Knight Piesold and Company, Denver, CO 80265, USA \\ 'United States Department of Agriculture, Animal and Health Inspection Service, Wildlife Services, National Wildlife Research Center, 4101 La \\ Porte Avenue, Fort Collins, CO 80521, USA
}

\begin{abstract}
We evaluated a radar-activated integrated hazing system for the protection of waterfowl at large contaminated ponds at a power plant. The hazing devices in the system included acoustic alarm calls, pyrotechnics and chemical repellents dispersed in the form of a bird tear-gas. Unlike, timed interval systems, or systems with random activation sequences, birds did not habituate to the demand-performance system tested. Over the course of a year, we documented that waterfowl were 12.5 times less likely to fly over the hazed contaminated ponds relative to a non-hazed control pond. Of the waterfowl that did fly over both ponds, the likelihood of landing on the hazed contaminated pond was 4.2 times less relative to the control. Hazing also altered the flight direction and altitude of waterfowl. Mortality during the year the hazing system was in place decreased by a factor 6.5 relative to previous years where the system was not in operation. Demand-performance integrated hazing systems show promise in protecting large areas where placement of operators is not practical for logistic, safety, or long-term cost reasons. Published by Elsevier Science Ltd.
\end{abstract}

\section{Introduction}

Human-wildlife conflicts occur in a variety of circumstances. In agricultural settings, for example, the need of the farmer is to prevent crop depredation by wildlife. This can be achieved by rendering the food resource unpalatable to the wildlife or by denying wildlife access to the commodity (Dolbeer et al., 1994). In industrial settings, regulatory requirements dictate that wildlife be protected from harm that may come about through their contact with processed materials or contaminants (Allen, 1990). In nuisance situations it may be desirable to keep wildlife off architectural structures to prevent damage to those structures or to

* Corresponding author. preserve an aesthetic quality of the structure, i.e., prevent fecal accumulation (Wright, 1982). Finally, there may be circumstances where an overabundance of commensal wildlife may place humans or their farm stock at some health risk (Feare et al., 1999). Deterrent devices and chemical repellents are used to exclude or move wildlife away from targeted areas where the conflicts occur, with the context of the situation dictating which deterrent method is most appropriate (Nolte and Mason, 1998).

Typical protective measures to keep birds away from areas include exclusion by use of netting, hazing, and chemical repellents (Hyngstrom et al., 1994). Chemical repellents, both primary and secondary (Rogers, 1980), are used to render a resource unpalatable, e.g., food or water, and as a consequence repellents remove the incentive for 
birds to visit the area where the protected resource occurs. Chemical repellents are expensive, and as currently commercially formulated are only useful as feeding deterrents. Thus, chemical repellents are generally not useful in industrial and nuisance situations (Clark, 1998). Exclusionary devices are quite successful, but engineering constraints and costs often limit the size of area that can be protected (Allen, 1990; Fuller-Perrine and Tobin, 1993). This is particularly vexing because in most industrial situations, processed materials may be placed in large holding ponds, covering hundreds of acres. Hazing techniques rely on the use of auditory and visual devices to scare birds away from an area, e.g., bird distress calls, pyrotechnics, propane exploders, flashing lights, effigies of humans or predators, and flagging (Greer and O'Connor, 1994). However, birds can rapidly habituate to these tactics if the use of such devices falls into a predictable pattern (Brush, 1971; Miligram et al., 1977; Bomford and O'Brien, 1990). Thus, hazing requires diligence on the part of managers to maintain the novelty, salience, and effectiveness of the stimuli.

Attempts have been made to design acoustic hazing systems that do not require constant operator attention (Martin and Martin, 1984). For example, interval timing devices solve the problem and expense of having to place operators in the field for lengthy periods of time. However, the predictability in the activation of the hazing devices sometimes results in rapid habituation to the devices by the targeted wildlife (Meyers, 1967). Randomization in the activation of devices results in an increase in the length of time the devices are effective, but ultimately, the target animals still habituate to the deterrent devices (Spanier, 1980). "Demand-performance" systems have been designed that prolong the effectiveness of the attached hazing devices even further. Such systems typically are activated by the motion (usually an infrared signature) or sound of the target animals. Such systems still have limitations in the distance they can detect the target, and their inability to couple the alarm signal with some form of aversive experience.

Other problems can occur for hazing systems. When personnel are placed in the field for prolonged periods they are subject to attention fatigue. Alternatively, economic, safety, or logistical constraints may preclude the placement of operators in the field. In principle, a hazing system that incorporated an alarm signal, negative aversive stimuli, and an automated "demand-performance" trigger should provide long term efficacy without requiring attendance by human operators (Bomford and O'Brien, 1990).

Recently, we had the opportunity to evaluate the effectiveness of an integrated hazing system that in- corporated alarm signals, chemical repellents, pyrotechnics, and a radar-activated triggering system (e.g., Johansson et al., 1994; Weber and Filas, 1994). Using radar images of the target animals allows the triggering system to be operable over larger areas while preserving the demand-performance nature of the hazing system.

The Jim Bridger Power Plant is a coal-fired power plant located in Point of Rocks, Wyoming, USA. The power plant uses soda liquor, consisting approximately of $25 \%$ sodium carbonate, from nearby trona (soda ash) processing plants to neutralize the acidity of water used in the flue scrubbers (Ramirez, 1992). Water in the scrubbers reduces sulfur dioxide emissions resulting from the burning of fossil fuel for energy. Typically, water used in the scrubbers is recycled several times and then discharged into nearby evaporation ponds. The flue gas desulfurization (FGD) liquor is high in sodium, chloride, sulfates, carbonates and bicarbonates. Because these ponds occur in an arid landscape they attract migratory aquatic birds, especially in the late fall and winter when other nearby bodies of water are dried out or have iced over. At temperatures below $23^{\circ} \mathrm{C}$, sodium decahydrate crystallizes on any solid object in or on the water. The salt crystallization on the feathers of birds destroys their insulation and buoyancy. Birds so affected usually die owing to hypothermia or drown due to the accumulations of minerals on their feathers. Taking into account the potential for avian mortality, and under pressure from Federal regulatory agencies, Pacificorp, the owners of the Jim Bridger Power Plant, initiated research into additional methods that would improve the efficacy of their bird deterrent program. Prior to initiation of this project, the Jim Bridger Power Plant employed standard methods of bird deterrence which consisted of human operators stationed at the power plant, and when needed, these operators would discharge a variety of pyrotechnic devices (bangers, screamers) to scare incoming birds away from the ponds. The operators were only employed during daylight hours. Thus, 24 $h$ protection was not provided, even though there remained a possibility of nocturnal movement of migratory waterfowl. The hazing system employed was developed by Knight Piesold and Company and uses radar activation to detect birds flying over defined airspaces and initiate activation of hazing devices positioned around the ponds (Weber and Filas, 1994). In this study three types of hazing devices were employed in concert: a bird repellent aerosol (Stevens and Clark, 1998); acoustic scaring devices; and pyrotechnics (Bomford and O'Brien, 1990). We evaluated the efficacy of the integrated system in preventing birds from using the FGD ponds during installation in 1996 and after placement in 1997. 


\section{Materials and methods}

\subsection{The integrated hazing system}

The integrated hazing system is a proprietary unit composed of a standard marine radar (Furuno model FR8100D) that emits a beam from a 6-ft rotating antenna (Weber and Filas, 1994). The entire unit is housed in a travel trailer. The radar can be adjusted to filter out wave action on the surface of the ponds, adjusted for detection range of birds, and adjusted for image resolution, i.e., adjust the threshold for detection as a function of the bird's size. In addition, software filters were employed to better resolve the alarm zones and eliminate ground clutter from the radar images. Echoes (reflections of the energy beam from birds) activated a control panel, which in turn activated relays that triggered the battery of deterrent devices according to a preselected set of criteria. An additional feature of the system is that the radar images can be stored in computer. In this way the hazing system not only serves as a detection system and a trigger, but also as a record of bird activity and flight patterns, the limit being the hard disk storage capacity of the controlling computer. For the time intervals selected in this study, radar images were stored once every $5 \mathrm{~s}$. Once a week, the radar images, saved as bitmap images, were transferred from hard disk to backup tapes and stored for subsequent analysis.

Initial installation for FGD pond number 1 began in the spring of 1996. Placement of hazing devices for FGD pond number 2 began in the fall of 1996. The integrated hazing system was fully operational for both FGD ponds after November 1996. Hence data reported for the hazing systems for 1996 include only the fall 1996 observations at FGD pond number 1. Data reported for the hazing system in 1997 include both ponds.

The sound system broadcasted a variety of animal

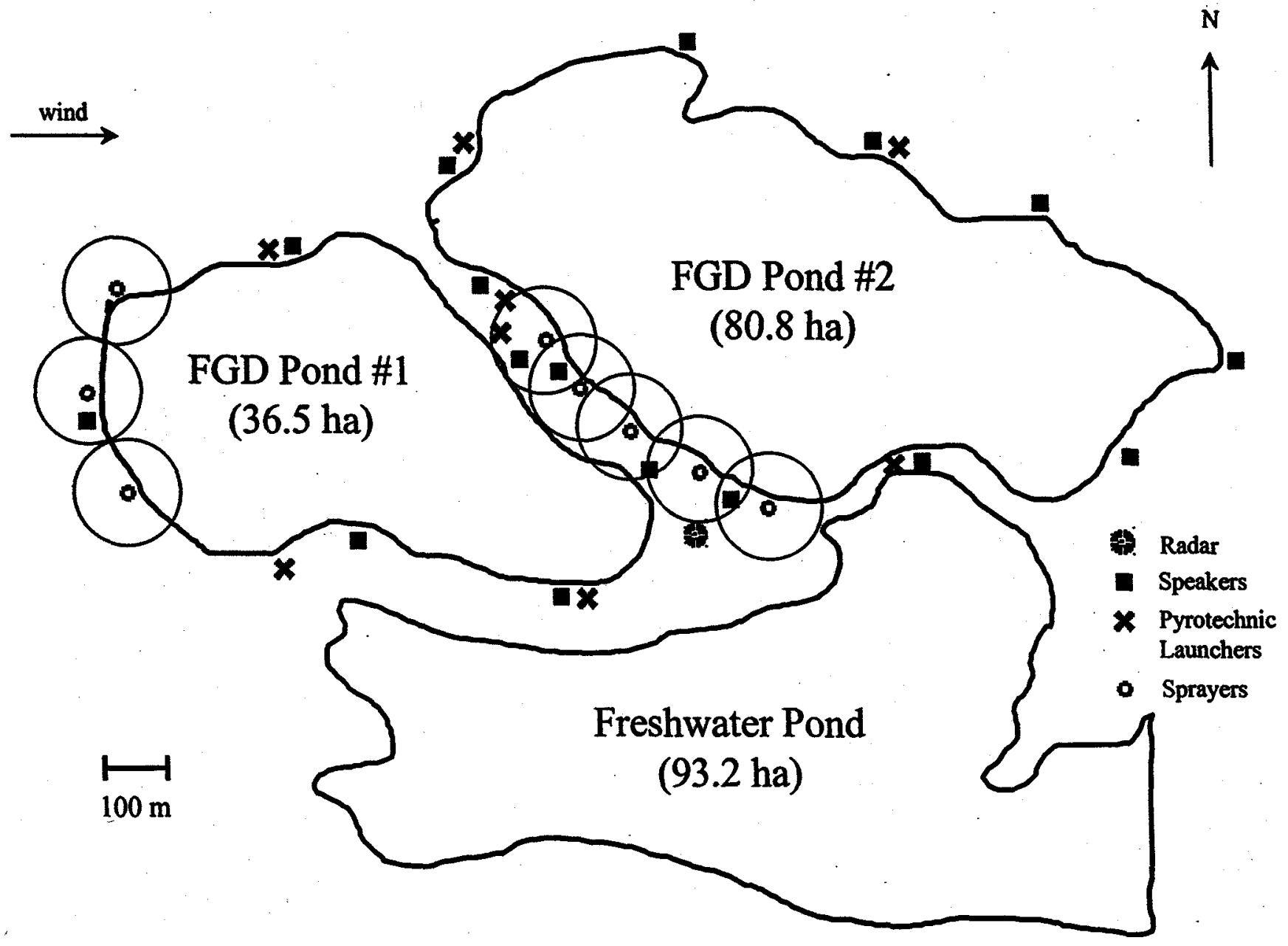

Fig. 1. A map of the freshwater and FGD ponds at the Jim Bridger Power Plant, Point of Rocks, Wyoming. Symbols depict placement of the hazing devices and control center. Circles around the sprayer symbols are maximum ranges for repellent concentrations for the aerosol dispersion. 
distress calls, e.g, recordings of screaming raptors, and vocalizations from injured animals (Boudreau, 1968). The sound system consisted of a recorder/ announcer, amplifier (TOA P-924, $240 \mathrm{~W}$ ), and six large horn speakers (Atlas DR-54, rated $136 \mathrm{db}$ ) on FGD pond number 1 and 10 speakers on FGD pond number 2 (Fig. 1).

The pyrotechnic launcher utilized "screamer" cartridges specifically designed to haze birds (Frings and Frings, 1967). Knight Piesold and Co. has designed a battery launcher that electrically ignites the cartridges. A set relay in the device switches the electrical current to the next tube for the next activation from the control panel. Thirty-six launches could be achieved prior to reloading.

Although chemical repellents are generally only applied to food to prevent ingestion of treated material by birds (Mason and Clark, 1992), we previously showed that aerosol delivery of an avian irritant could alter animal behavior (Stevens and Clark, 1998). In effect, we incorporated a birdspecific tear-gas into the integrated hazing system. High pressure aerosol sprayers (New Waste Concepts, Perrysville, $\mathrm{OH}$ ), utilizing the bird deterrent, methyl anthranilate (Clark, 1998), were placed around the FGD ponds. Sprayers were only activated after pyrotechnic launches and acoustic activations, and only if the radar system detected that birds were still within the no-fly zone.

We modeled the probable dissipation of the aerosol clouds for the prevailing environmental conditions using weather data gathered by Pacificorp and Gaussian puff-plume atomospheric models (Clark and Shah, 1992; Trinity Consultants, Inc.). Based on these preliminary models we positioned the sprayers around the FGD pond number 1 to achieve maximum coverage of the ponds (Fig. 1). However, it became apparent that the latency for plume dispersal was too great to target birds with appropriate concentrations of aerosol when the sprayers were placed on the far upwind side of a pond. Thus, we reasoned that any bird coming from the freshwater pond to FGD pond number 2 could best be intercepted with chemical repellent if the sprayers were placed along the isthmus between the two ponds (Fig. 1). We verified the coverage afforded by individual sprayers by placing oil sensitive paper targets at various distances from the aerosol source under different weather conditions.

Placement of the pyrotechnic and acoustic devices was determined from studies of spatial bird use by Jim Bridger personnel. The power to control the detection system was achieved by tapping into nearby power lines. Power to individual delivery units was derived secondarily through relays and the power supply from the control shed.

\subsection{Quantification of bird behavior by radar images}

Two sets of radar images were selected for detailed analysis once each week from late April to the end of May 1997 (26 April to 31 May) using a stratified sampling design. Each set of images consisted of a 2-h sampling period prior to $(0600-1300 \mathrm{~h})$ or after (1300$2000 \mathrm{~h}$ ) solar noon, resulting in $20 \mathrm{~h}$ of radar images for all three ponds (each radar image included the airspace for all three ponds). Radar scans were saved at 5 $s$ intervals, resulting in 14,400 bitmap radar images. Bitmap images were subsampled at 5 min intervals for detailed inspection, resulting in a sample size of 240 radar images. Two observers, blind to the identity of ponds, were trained to inspect the images and count the number of intrusions over the airspace of each pond. Intrusions were defined as an isolated illumination of a bitmap pixel or an associated clump of illuminated pixels. Thus, an intrusion could represent an individual or a flock of birds (of about teal size or larger). Changes in profile of the flock or bird precluded a more detailed characterization of these static radar images. The 5-min sampling interval also minimized the chances of recording flight activity of the sampled individual or group of birds, i.e., circling flight behavior. By analyzing data from contiguous radar images (resolution of $5 \mathrm{~s}$ ) we were able to satisfy ourselves that this interval did not indeed include the same set of birds for an intrusion event.

\subsection{Quantification of bird behavior by direct observation}

A ground observer monitored bird activity intermittently. During 1996, a total of 36.25 and $31.25 \mathrm{~h}$ was spent monitoring bird activity at the fresh water and FGD pond number 1 , respectively, using a time stratified sampling scheme (April-August). During 1997, a total of 18.0 and $36.5 \mathrm{~h}$ was spent monitoring the freshwater and the two FGD ponds, respectively (April-November). The number of flights over the ponds and the number of flights that ended in a bird landing on the ponds' surface was noted for waterfowl and non-waterfowl. In addition, the bearing of incoming and outgoing fights was recorded, as well as an estimate of altitude of level flight. These "groundtruthing" data on bird behavior were significant in verifying the accuracy of the radar image analysis.

In addition to the bird flight activity data, we obtained information from the bird rescue team maintained by Pacificorp. These data included the number of rescues of birds made at the FGD ponds, and the number of birds that died as a function of time of year. 


\subsection{Data analysis}

We used odds-ratios as a descriptive analysis of bird behavior by direct observation (Fleiss, 1973). We used a log-likelihood analysis to discriminate treatment effects of the hazing system for the radar image observations (Bishop et al., 1975), and circular correlations to test the hypotheses about expectations of flight headings (Batschelet, 1981).

\section{Results}

An analysis of a subset of radar images for the month of May 1997 showed that the cumulative number of incursions by individuals and groups of individuals was lower in the FGD ponds relative to the freshwater ponds, and that there was no apparent difference in detectable incursions between the exterior and interior of the ponds' airspace (Fig. 2).

The pattern of flight activity over the ponds was supported by direct observation as well (Fig. 3). Waterfowl were 12.5 times more likely to be seen flying over the freshwater pond relative to the two FGD ponds. More importantly, waterfowl flying over the freshwater ponds were 4.2 times more likely to land relative to birds fiying over the two FGD ponds, implying that the integrated hazing system was effective at preventing landings of waterfowl. More birds of non-waterfowl species (mostly shorebirds) flew over the FGD ponds. However, non-waterfowl birds flying over the freshwater ponds were seven times more likely to land.

There were other indications that the flight activity of the integrated hazing system affected the flight patterns of waterfowl. Waterfowl flying over the freshwater pond were more likely to approach and leave the pond at lower altitudes (Fig. 4). Indeed, waterfowl flying over FGD ponds were 11.5 times more likely to approach the pond at altitudes greater than $50 \mathrm{ft}$, and 2.4 times more likely to leave the pond area at altitudes of $50 \mathrm{ft}$ or more. The mean flight headings of waterfowl also were affected by the hazing system (Fig. 5). Waterfowl approached all ponds into the prevailing winds (FGD pond $1, t=1.52$; FGD pond 2 , $t=1.86$; freshwater pond, $t=0.44$, all with $P>0.05$ ). Departure trajectories varied among ponds. For the freshwater pond, waterfowl took off with the prevailing wind as expected $(t=0.49, P>0.05)$. However, departure trajectories for waterfowl over the two FGD ponds differed from the prevailing winds (FGD pond $1, t=3.18$; FGD pond 2, $t=1.93$, with both at $P<0.05)$. Rather, the departure trajectories for waterfowl over the FGD ponds were more in keeping with the direction of the freshwater pond (FGD pond 1, $t=1.82$; FGD pond $2, t=1.69$, with both at $P<0.05$ ).

In the final analysis, the efficacy of the integrated

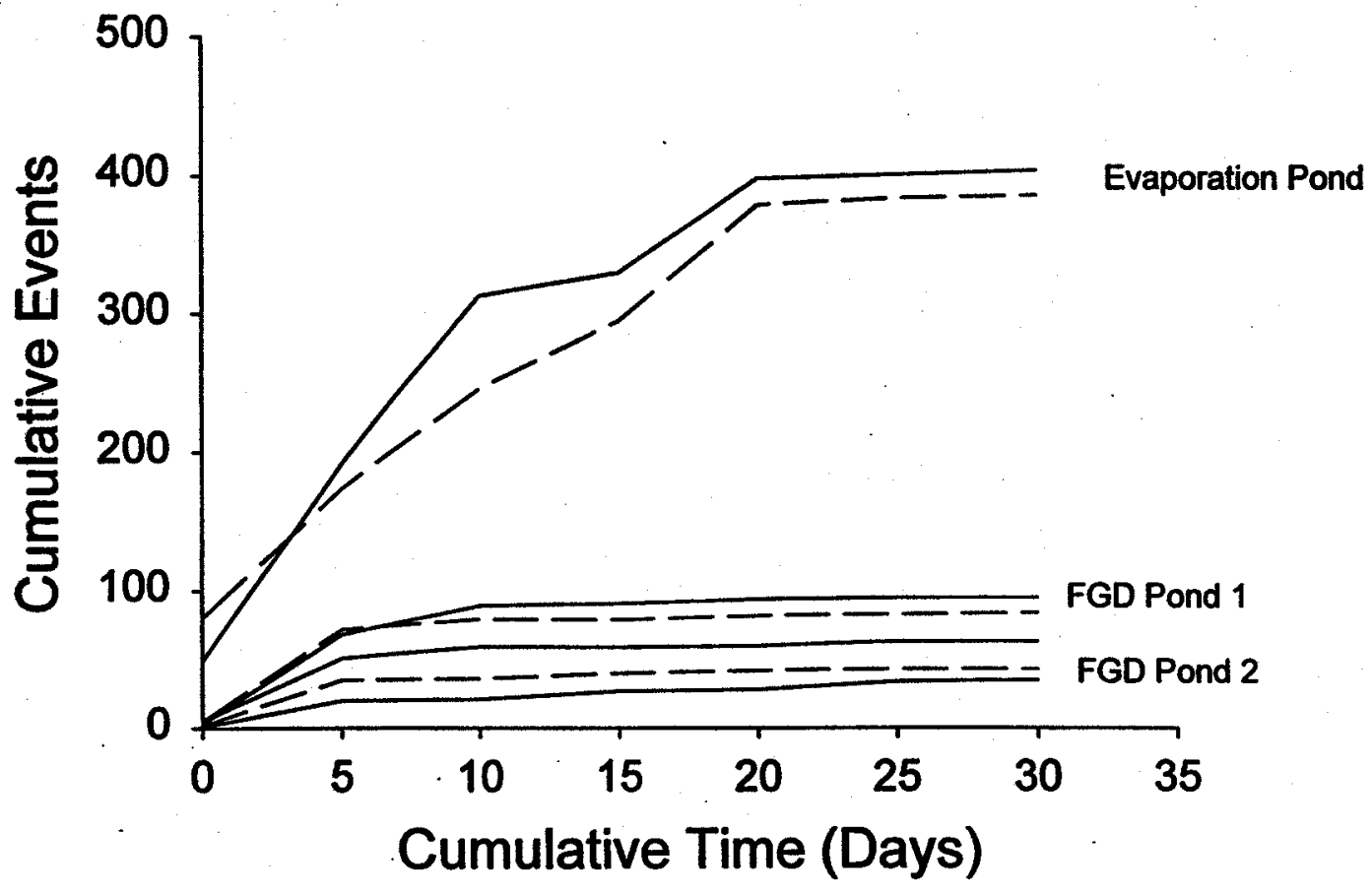

Fig. 2. Cumulative frequency distributions of the number of bird incursions over the freshwater and FGD ponds at the Jim Bridger Power Plant. Exterior counts (dashed lines) are birds detected within $20 \mathrm{~m}$ of the shoreline. Interior (solid lines) counts are birds detected more than $20 \mathrm{~m}$ from the shoreline, towards the interior of the ponds. 


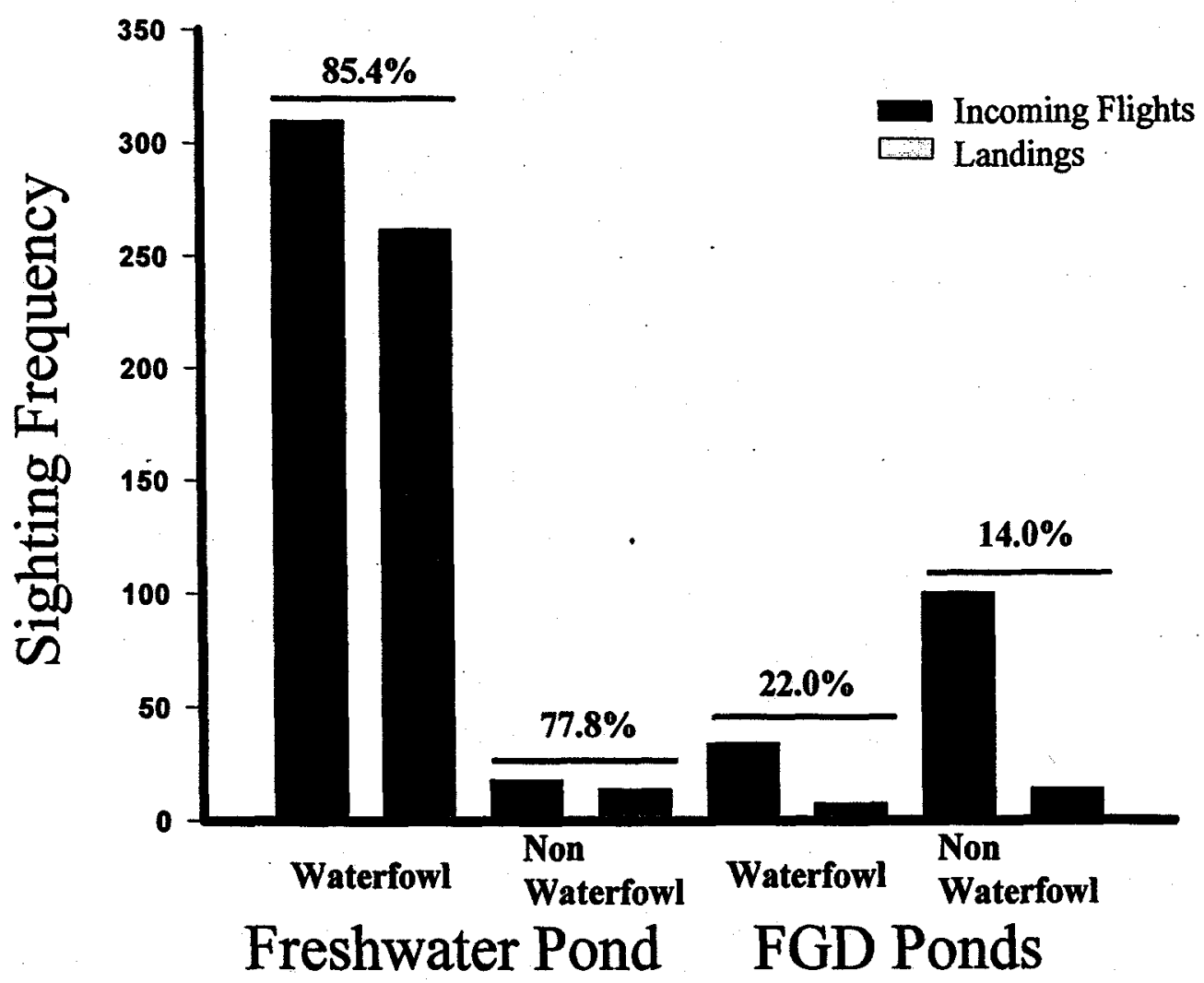

Fig. 3. The frequency distributions of the number of bird flights over the freshwater and FGD ponds, and the frequency of landings on those ponds. Percentages are indications of the number of flights that resulted in landings.

hazing system will be judged on its ability to save the lives of birds over the long term in a cost-effective manner. The manual bird hazing program began in 1993 and records on the number of birds rescued from the surface of the FGD ponds and mortality were maintained since. However, because this was the first year of the program, efforts were sporadic and the

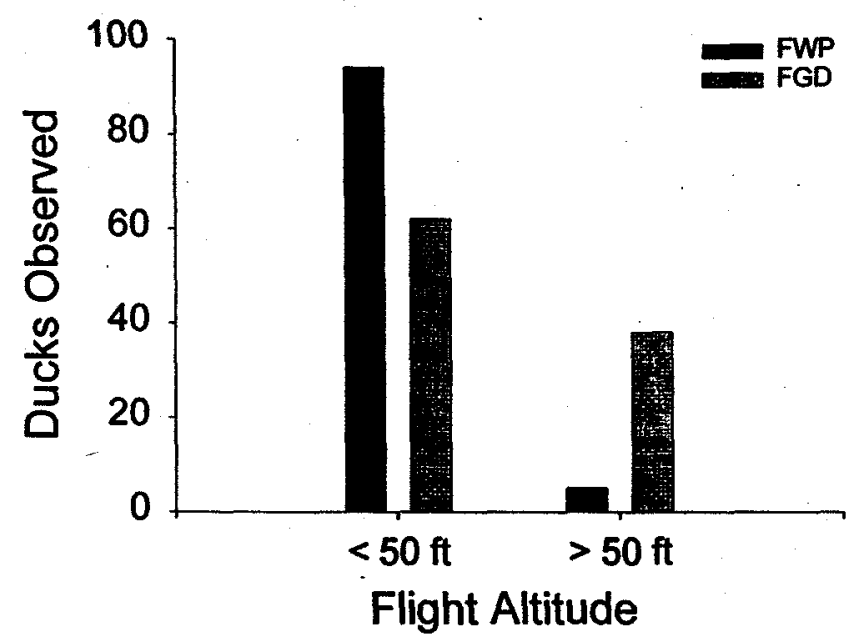

Fig. 4. The frequency of incoming and outgoing flight altitudes over the freshwater and FGD ponds. data are not presented. Using records from 1994 to 1997, the bird rescue team at the Jim Bridger Power Plant indicated that the largest peak of bird use on the ponds occurred between August and October of each year with a minor peak in May. In the years preceding installation (1994-1995) the monthly bird rescues off the FGD ponds ranged from 75 to 250 waterfowl. During 1996 the hazing system was installed on FGD pond number 1 in the spring, and on FGD pond number 2 during the fall migration. During 1996 the monthly fall rescues ranged from 50 to 100 waterfowl. During 1997 when the system was fully operational, the number of rescues ranged from 10 to 40 waterfowl.

The total number of birds recovered from the surface of the two FGD ponds ranged from 685 to 714 during the two years preceding the installation of the integrated hazing system (1994-1995). During the transition year, i.e., the year of installation, when the principal protection was still manual operation with the addition of some sporadic operation of the integrated hazing system on FGD pond number 1, the number of rescues was 859 . During 1997, when the integrated hazing system was fully operational, the number of bird rescues from the FGD ponds was 210 (Figs. 6 and 7). The reduced number of rescues in 1997 is consistent with the radar images which indicated that bird 
flights over the FGD ponds were reduced relative to the control. The rescue data are also consistent with the manual observations that indicated reduced bird flights over and landings on FGD ponds. Personnel at the Jim Bridger Power Plant estimated that the integrated hazing system saved 4000 man-hours in 1997 (Jim Doak, personal communication). The efforts of the bird hazing teams shifted from hazing to periodic sweeps of the FGD ponds to look for birds on the surface of the FGD ponds and implement rescue efforts.

\section{Discussion}

In so far as this was an evaluation of an on-going operation at a commercial business, where operations were subject to legal scrutiny under the Migratory Bird Treaty Act, attempts to experimentally manipulate the system were not made, i.e., to disengage it, for periods of time to determine what effects such manipulations might have on bird behavior. Rather, this study should be viewed as a case study, where certain longitudinal comparisons could be systematically made for the purposes of drawing inferences about the efficacy of the system.

The system appeared to achieve all of its intended goals in the short-term. After considering the radar images and ground observations we found that fewer waterfowl flew over and landed on the protected FGD ponds, suggesting that the hazing system was effective at keeping waterfowl away from large areas of protected space for long periods of time, i.e., throughout the year. We infer from these data that waterfowl do not habituate to the system. When waterfowl did fly over the FGD ponds they did so at higher altitudes, for which we infer that there was some avoidance of the hazing devices. The arrival and departure trajectories over the ponds suggested to us that waterfowl deviated from normal flight patterns over the FGD ponds and flew, not along the vector of the prevailing wind, but towards the freshwater ponds after being hazed. This pattern suggested to us that waterfowl became familiar with the area. It is arguable that the waterfowl may have developed an expectation that they would not be harassed at the freshwater pond, and that escape to a sanctuary overrode energetic considerations influencing flight patterns. That is to say, there was no indication that hazed birds left FGD ponds with the wind and then circled to the freshwater ponds. Rather, the flight pattern after hazing was directly towards the non-hazed freshwater ponds, perpendicular to the prevailing wind.

We cannot attribute how each of the hazing devices worked individually to haze the birds. Modeling efforts and empirical observations for the chemical repellent suggested to us that the area of coverage for this system was limited. Spatial coverage limitations not withstanding, pilot trials on waterfowl indicated that the birds were highly reactive to the repellent cloud and moved away from the source and plume. However, we did not attempt to make such direct observation for the effects of aerosol repellents over the FGD ponds. It was easier to infer what effects the pyrotechnics had on bird behavior. As rockets were launched, birds perceptibly changed their flight paths away from the pyrotechnic. Pyrotechnics are self-reinforcing in that they

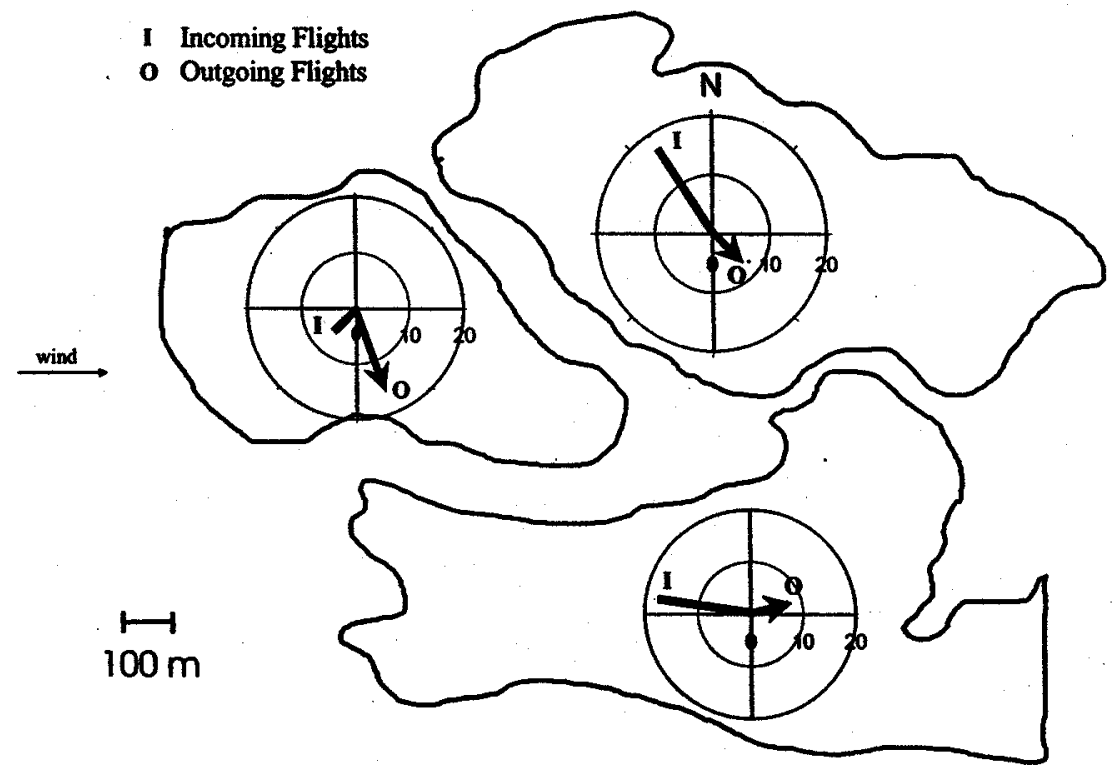

Fig. 5. The mean frequency of incoming (flat bars) and outgoing (arrowed bars) flights as a function of compass bearing for waterfowl over the freshwater and FGD ponds. 

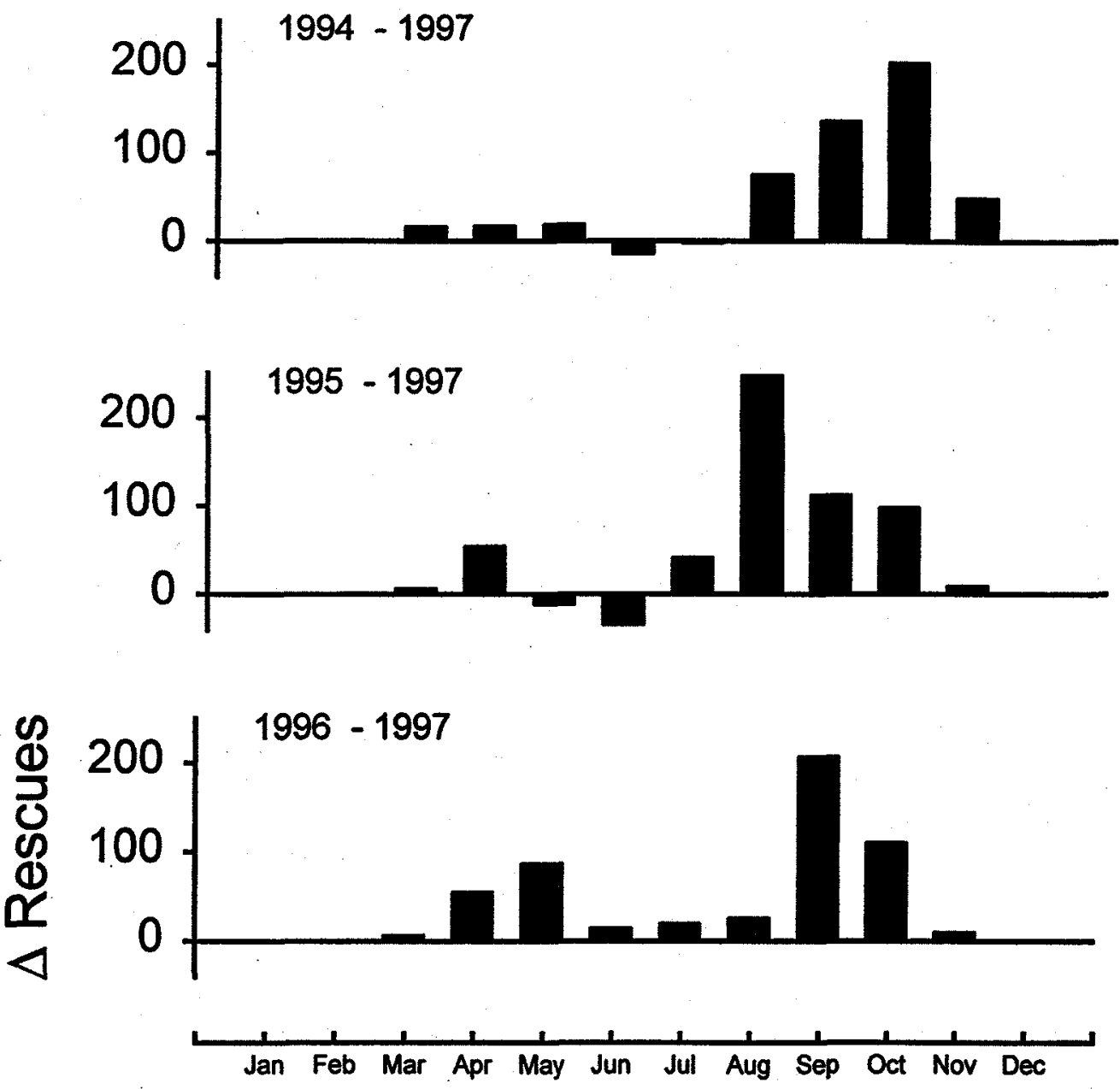

Fig. 6. The frequency of bird rescues on FGD ponds as a function of time of year. $\Delta$ Rescues is defined as the number of rescues in a given year preceding operation of the integrated hazing system minus the number of rescues in 1997, the year the system was in operation on both FGD ponds.

give the illusion of pursuit, in addition to providing visual and acoustic alarm signals. Pyrotechnics also

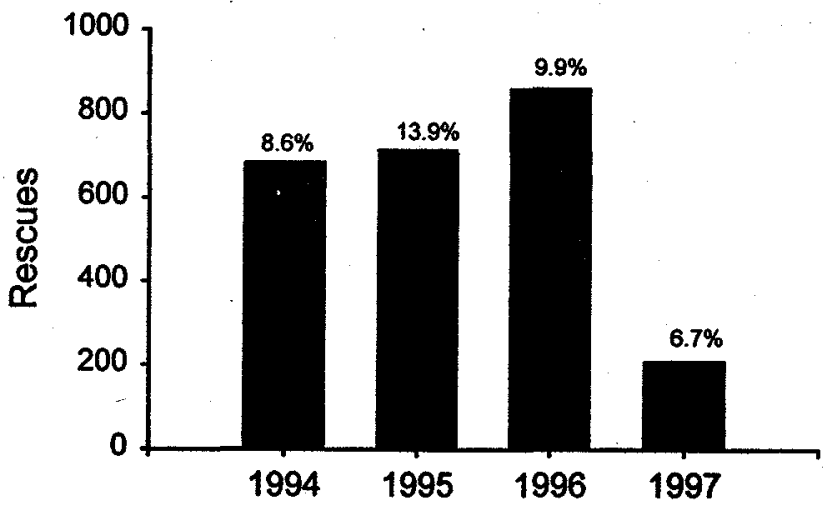

Fig. 7. The total number of rescues on the FGD ponds as a function of time. The percentages reflect the proportion of birds rescued from the ponds' surface that ultimately died. The number of mortalities was reduced from 77 to $86 \%$ during 1997 relative to the three years preceding installation of the integrated hazing system. can act to reinforce the alarm signals emanating from the speaker system.

The savings in man-hours to maintain a hazing program, the depreciation of a capital investment, and the reduction in the number of waterfowl rescues, and by implication the potential for waterfowl mortality, were apparent successes of the system in 1997. Thus, we conclude that the system and future adaptations have potential in keeping birds from using large areas. The obvious disadvantages of the system are the cost, initial installation and placement, power sources, and skilled labor required for maintenance. Additionally, radar-activated systems are currently only practical where the terrain is flat, e.g., ponds and fields. Otherwise, ground clutter tends to trigger the system unless extensive software filters are incorporated to mask such clutter. Finally, for industries and agricultural settings where violations of the Migratory Bird Treaty Act do not occur, or where economic losses do not justify the costs of installation and operation, this system 
may not be appropriate. However, the system shows promise when such considerations are important.

\section{Wildife management implications}

Habituation to hazing systems is a critical shortcoming of existing technologies. Demand-performance systems, as demonstrated by this radar activated system, show great promise in eliminating this shortcoming. Thus, the goal of protecting large areas from bird use over long periods of time is achievable. What remains to be determined is whether costs and technical aspects of demand performance systems can be lowered without sacrificing efficacy.

\section{Acknowledgements}

Sponsorship and funds for this project were provided by a cooperative agreement between Knight Piesold, Ltd. and the National Wildlife Research Center (NWRC) (97-7047-0319 RA), and a cooperative agreement between the NWRC and Colorado State University (97-7047-0285 CA, 032096). We thank Pacificorp Power Company for their support, and K. Dyer for assistance in reading radar generated bitmap images.

\section{References}

Allen, C.H., 1990. Mitigating impacts to wildlife at FMC Gold Company's Paradise Peak Mine. In: Proceedings Nevada Wildlife/Mining Workshop, pp. 67-71.

Batschelet, E., 1981. Circular Statistics in Biology. Academic Press, New York pp. 371.

Bishop, Y.M., Fienberg, S.E., Holland, P.W., 1975. Discrete Multivariate Analysis. MIT Press, Cambridge, MA pp. 557.

Bomford, M., O'Brien, P.H., 1990. Sonic deterrents in animal damage control: a review of device tests and effectiveness. Wildlife Society Bulletin 18, 411-422.

Boudreau, G.W., 1968. Alarm sounds and responses of birds and their application in controlling problem species. Living Bird 7, $27-46$.

Brush, F.R., 1971. Aversive Conditioning and Learning. Academic Press, New York pp. 626.

Clark, L., 1998. Physiological, ecological, and evolutionary bases for the avoidance of chemical irritants by birds. In: Nolan, V., Ketterson, E. (Eds.), Current Ornithology, vol. 14. Plenum Press, New York, pp. 1-37.

Clark, L., Shah, P.S., 1992. Information content of prey odor plumes: what do foraging Leach's storm petrels know? In: Doty, R.L., Muller-Schwarze, D. (Eds.), Chemical Signals in Vertebrates, vol. 6. Plenum Press, New York, pp. 421-427.
Dolbeer, R.A., Avery, M.L., Tobin, M.E., 1994. Assessment of field hazards to birds from methiocarb applications to fruit crops. Pesticide Science 40, 147-161.

Feare, C.J., Sanders, M.F., Blasco, R., Bishop, J.D., 1999. Canada goose (Branta canadensis) droppings as a potential source of pathogenic bacteria. Journal of the Royal Society for the Promotion of Health 119, 146-155.

Fleiss, J.L., 1973. Statistical Methods for Rates and Proportions. Wiley, New York pp. 223.

Frings, H., Frings, M., 1967. Behavioral manipulation (visual, mechanical, and acoustical). In: Kilgore, W.W., Doutt, R.L. (Eds.), Pest Control. Academic Press, London, pp. 387-454.

Fuller-Perrine, L.D., Tobin, M.E., 1993. A method for applying and removing bird-exclusion netting in commercial vineyards. Wildlife Society Bulletin 21, 47-51.

Greer, R.D. O'Connor, D.J., 1994. Waterbird deterrent techniques. Marine Spill Response Corporation, Washington, DC. MSRC Technical Report Series 94-003, pp. 44.

Hyngstrom, S.E., Timm, R.M., Larson, G.E., 1994. Prevention and Control of Wildlife Damage. University of Nebraska Cooperative Extension, United States Department of Agriculture, Washington, DC.

Johansson, C., Hardin, P., White, C.M., Kremer, S., 1994. BirdAvert ${ }^{\circ}$ System test results. Internal document. Peregrine Systems, Inc., Salt Lake, UT.

Martin, L.R., Martin, P.C., 1984. Research indicates propane cannons can move birds. Pest Control 52, 52.

Mason, J.R., Clark, L., 1992. Nonlethal repellents: the development of cost-effective, practical solutions to agricultural and industrial problems. Proceedings Vertebrate Pest Conference 15, 115-129.

Meyers, A.K., 1967. Contradictory evidence for aversion to auditory stimuli resulting from different test methods. Journal of Comparative Physiological Psychology 64, 171-175.

Miligram, N.W., Krames, L., Alloway, T., 1977. Food Aversion Learning. Plenum Press, New York pp. 262.

Nolte, D.L., Mason, J.R., 1998. Bioassays for mammals and birds. In: Haynes, K.F., Millar, J.G. (Eds.), Methods in Chemical Ecology: Bioassay Methods, vol. 406. Kluwer Academic Publishers, Norwell, MA, pp. 326-395.

Ramirez, P., Jr., 1992. Trace element concentrations in flue gas desulfurization wastewater from the Jim Bridger Power Plant, Sweetwater County, Wyoming. US Fish and Wildlife Service, Contaminant Report R6/703/92, Cheyenne, WY.

Rogers, J.G., 1980. Conditioned taste aversion: its role in bird damage control. In: Wright, E.N., Inglis, I.R., Feare, C.J. (Eds.), Bird Problems in Agriculture. British Crop Protection Council, London, pp. 173-179.

Spanier, E., 1980. The use of distress calls to repel night herons (Nycticorax nycticorax) from fish ponds. Journal of Applied Ecology 17, 287-294.

Stevens, G., Clark, L., 1998. Bird repellents: development of avian-specific tear gases for resolution of human-wildlife conflicts. International Biodeterioration and Biodegradation 42, 153-160.

Weber, R.A., Filas, B.A., 1994. Experimental radar-activated hazing system. In: Proceedings 6th Symposium, Issues and Technology in the Management of Impacted Wildlife. Glenwood Springs, $\mathrm{CO}$.

Wright, E.N., 1982. Bird problems and their solution in Britain. Proceedings of the Vertebrate Pest Conference 10, 186-189. 